\title{
Sonido Ritual, Campo de Fuerza y Espacialidad Existencial: Una Estética no Musicológica de los Bailes Chinos $^{1}$
}

\author{
Ritual Sound, Force Field, and Existencial Spatiality: a Non- \\ Musicological Aesthetics of the Bailes Chinos
}

\author{
Gabriel Castillo Fadic \\ Instituto de Estética, Pontificia Universidad Católica de Chile \\ gcastilf@uc.c \\ Patricio de la Cuadra \\ pcuadra@uc.cl \\ Benoît Fabre \\ LAM, Université de París 6 Pierre et Marie Curie, Institut Jean le Rond d'Alembert, París \\ benoit.fabre@upmc.fr \\ François Blanc \\ LAM, Université de París 6 Pierre et Marie Curie, Institut Jean le Rond d'Alembert, París
}

Centro de Investigación en Tecnologías de Audio, Instituto de Música, Pontificia Universidad Católica de Chile

Resumen - Los bailes chinos de la zona central de Chile constituyen una potencia expresiva que combina la ejecución de flautas rituales, el movimiento coreográfico y el canto. Con independencia del interés, los valores y las categorías analíticas que suscitan en los estudios de cultura tradicional, ellos pueden ser leídos directamente, primeramente, fenomenológicamente, como una compleja operación simbólica y ritual que verifica el carácter existencial del espacio intervenido por el sonido y por cuerpo. El presente artículo busca esa lectura directa y atenta a la forma misma, literal, del acontecer, desde una aproximación mixta, filosófica y físico-acústica. Desde ella se procura establecer un sistema estético de correspondencias que pone en tensión forma física, forma existencial y sentido.

Palabras clave: Baile chino, acústica de las flautas de chinos, sonido ritual, devenir no musical, Gilles Deleuze.

Abstract - The Bailes chinos from Central Chile are an expressive power that combines ritual flutes, choreographic movement, and singing. Not just depending from the interests, values and analytical categories that might arise in the traditional studies of culture, the Bailes can be read straightforwardly, mainly, phenomenological, as a complex symbolic and ritualistic operation that validates the existential character of a space intervened by sound and the body. The present article looks for that straightforward reading, and attempts on the very form, literal, from the everyday occurrence, and from a mix approximation, both philosophical and physical-acoustical. From that spot, the article will try to establish an aesthetical system of correspondence that will tense the physical form, the existential form and the sense.

Keywords: Baile Chino, Acoustic of the Chinos' flutes, ritual sound, non-musical becoming, Gilles Deleuze

\footnotetext{
El presente artículo expone parte de los resultados obtenidos en una investigación financiada por el Fondo de Fomento de la Música, ECOS-CONICYT y FONDECYT, y da cuenta, puntualmente, del estudio de bailes chinos observados entre mayo y diciembre del 2009 en distintas localidades de la zona costera y precostera situadas entre Olmué y Puchuncaví (Valle Alegre, Los Maitenes, Los Maquis, Pucalán, Loncura y Cai-Cai). Quisiéramos expresar nuestro profundo reconocimiento a los investigadores del Museo Precolombino José Pérez de Arce y Claudio Mercado, autores en Chile de una obra antropológica fundamental sobre el tema, quienes generosamente nos ayudaron a iniciarnos en nuestro estudio.
} 
Los bailes chinos ponen en acción una máquina, o una maquinaria, sonora. Pero aunque su potencia expresiva resida considerablemente en las cualidades de la emisión del sonido, lo que desaparece, o lo que se supera, son las funciones simbólicas que la musicología histórica, y gran parte de la tradición etnomusicológica, definirían como propiamente musicales. A excepción relativa del canto del alférez, figura sacerdotal, que establece precisamente un nexo crítico con la música religiosa vernácula de tradición hispanoárabe, la ejecución colectiva de las flautas rituales anticipa una suerte de devenir no musical, o premusical, o paramusical, que sin constituirse nunca como música en potencia, se articula, sin embargo, como potencia de sonido. No hay obra, ni hay pieza por ejecutar, una pieza cuyo debut podría anticiparse con una imperceptible señal concertada, sino más bien un estado de resonancia por alcanzar, que se verifica como una puesta en marcha de la máquina sonora. Cuando los dos ejecutantes de las flautas punteras coordinan, con la mirada, la precisa alternancia de ambos ataques, están, fundamentalmente, marcando un gesto de arrastre o de aspiración, un gesto de contacto o de ignición, sobre el que la máquina sonora puede levantarse y adquirir una forma. Forma de nube o de campo de fuerza, ella aísla a los actuantes del espacio común que los precedía, y abre para ellos un espacio propio cuya integridad y capacidad de desplazamiento dependen de la administración de un doble régimen expresivo: a) de circulación y compleción sonoquinética y, b) de alternancia de movimientos, velocidades e intensidades.

Independientemente del estilo y del tiempo histórico, toda forma musical, ya sea como ritornelo ${ }^{2}$ preconsciente o bien como composición de autor o comunidad, supone un acto de renuncia, una operación gigantesca de selección y omisión donde la identidad del gesto (una línea de voz, un pasaje instrumental), su contorno, se dibuja en el vacío de todos los sonidos que, siendo posibles, no han sido emitidos. Las flautas de chinos, en cambio, han sido diseñadas para colmar el espacio posible. Tanto los patrones de construcción como de ejecución de las flautas, exigen una extensión, una réplica en la proyección grupal - o, como en las grandes fiestas, en la superposición de grupos-, del cluster que puede ser obtenido individualmente en cada una de ellas (ver Recuadro 1 en Anexo). Ellas no tienen por objeto ofrecer al ejecutante una alternancia de posibilidades, como el aprendizaje de una gama o de variantes de ataque, al interior de un espectro sonoro, puesto que la exposición misma y simultánea del espectro posible es en sí la finalidad absoluta de la ejecución. Flautas no del horror vacui sino, más bien, del amor plenitatis, o de la potentia plenitatis. El sonido compone aquí, simultáneamente, todos los sonidos de una nube, de un campo de fuerza o de energía, que protegerá a los chinos, en su abandono del mundo, de las fuerzas del caos. "Cuando voy chineando siento eso que nos pasa a todos; vai metido ahí, no pensái en nada, vai chineando no más, entregándote entero. De repente te ponís a chinear, te encerrái en la cosa, vai como en otro mundo» (Díaz, cit. en Mercado y Rondón, 33$)^{3}$. Considerando solo los elementos sonoros, la operación de compleción se realiza tanto en la verticalidad del instante, como cluster de frecuencias, como en la horizontalidad de la secuencia temporal, como circularidad en la alternancia de los soplidos de ambas filas ${ }^{4}$ de ejecutantes o incluso como alternancia circular, vale decir como alternancia que nutre un gesto común en el que la dualidad de ataques se marca y

\footnotetext{
En el sentido en que lo entienden, como veremos más adelante, Gilles Deleuze y Félix Guattari.

Guillermo Díaz, chino puntero de Pucalán.

Los chinos se disponen en dos filas paralelas de entre diez y veinticuatro ejecutantes, por orden decreciente en el tamaño de las flautas, desde las «punteras» a las «coleras».
} 
se disipa simultáneamente. Desde su construcción, la calidad del diseño de las flautas es evaluada por su capacidad de emitir un sonido que pueda «dar la vuelta» ${ }^{5}$. Durante su ejecución, la dualidad del ataque de ambas filas debe ser percibido como un pulso, pero nunca como un corte o una cesura en la emisión del flujo sonoro, que debe volverse un flujo continuo, un enjambre cuya totalidad, en términos de fenómeno acústico, supera la pura adición de sus componentes. Componentes que por separado "gorgorean», "gargantean», «lloran», «gansean», «catarrean» o «pitean», pero que en estado de nube, o de masa acústica, adquieren una forma propia que reorganiza los efectos particulares en planos y texturas nuevas que superan incluso su pura descripción física, o bien que se proyectan en una escisión entre la descripción física y la percepción acústica. José Pérez de Arce («Sonido rajado»), por ejemplo, postula la inexistencia de una fundamental en el conjunto de sonidos emitidos por una flauta de chino. Inexistencia que a su vez Wright y Campbell refutan amparados en una evaluación psico-acústica del fenómeno. La analítica fenomenológica acústica revela el carácter profundamente existencial de la percepción sonora (ver Recuadro 2 en Anexo). El fenómeno físico puede prestar a la audición una capacidad de invención y de intención que lo sobrevive y lo prolonga en el plano de la percepción fenomenal en el que se sitúan, en diferentes rangos de intensidad, tanto los ejecutantes directos de la máquina sonora, como quienes son alcanzados por ella de modo presencial. Estos son los «efectos fantasmas» del fenómeno físico, que se completan y se verifican en la fenomenología de la audición, vale decir, en la existencialidad de la percepción sonora.

Decíamos también que la máquina sonora abre, y se abre a, una espacialidad, marcada por una alternancia de movimientos, velocidades e intensidades. Los chinos emplean convencionalmente la palabra «baile» para describir cada uno de los elencos territoriales de actuantes. Pero en estricto rigor, así como los flautas de chinos establecen un devenir no musical de la máquina sonora, los movimientos corporales de los ejecutantes establecen un devenir no danzante del baile. De hecho los grandes antagonistas de la máquina sonora, en el espacio ritual son, precisamente, los «danzantes», considerados como cofradías ajenas al territorio, incluso cuando son integradas por habitantes de una misma comunidad, y los cantantes (el canto del párroco o de la comunidad parroquial institucionalizada $)^{6}$, a quienes los chinos disputan la potestad mediúmnica. En el plano de la emisión sonora, un bombero marca el pulso de la alternancia circular y los cambios permanentes de tempo; en el plano del movimiento y la coreografía lo hace un tamborero, que se desplaza entre ambas filas de ejecutantes mostrando las «mudanzas» que deben seguir cuando no se está tocando «detenido». Los movimientos de los ejecutantes no son independientes de la calidad del ataque instrumental. Estos satisfacen, por una parte, una demanda aeróbica. La hiperventilación que genera la profundidad de la inspiración necesaria para exhalar el volumen de aire que se requiere para soplar adecuadamente las flautas, es compensada con una sobre exigencia física: avanzar, girar, flectar las piernas en una especie de sentadilla, gestos que son rematados, con intensidad variable, con un

Fórmula técnica empleada por Daniel Ponce, prestigioso constructor de flautas de la zona de El Venado, Quebrada de Alvarado, Olmué, entrevistado el 27 de marzo del 2009.

6 En Valle Alegre, por ejemplo, durante la primera «chineada» de mayo del 2009, el párroco, de origen italiano, procuró por todos los medios, incluso con la ayuda de un equipo de amplificación, imponer sobre el sonido de las flautas una canción de su agrado, muy pobre en su estructura musical y en su letra, que forzaba a repetir a la comunidad acompañado de un guitarrista y un acordeonista. Una situación similar se produjo dos meses después en la gran fiesta de San Pedro de Loncura. 
movimiento de caída, como en el purrun mapuche, o como en algunas danzas derviches o de meditación. Por otra parte, la mayor o menor brusquedad del movimiento de caída, que coincide preferentemente con el gesto de exhalación, y que permite así una súbita descompresión del diafragma, refuerza la calidad del ataque y determina sus posibles variaciones (ver Recuadro 1 en Anexo). El movimiento corporal es constitutivo del gesto de ejecución sonora. Pero no solo lo constituye y lo determina, como un tallo o un apoyo del ataque, sino que también replica la relación de colmado espacial que atribuíamos a la circularidad y amplitud del flujo sonoro. Aunque en algunos momentos de detención o de marcha simple el movimiento corporal remite solo a un leve balanceo del tronco, las «mudanzas», propiamente tales, se estructuran sobre combinatorias de movimientos de barrido horizontales (tipos de giros) y verticales (tipos de sentadillas), que replican una simbólica de la espacialidad absoluta: latitudo, longitudo, sublimitas y profundum ${ }^{7}$.

Cuando el campo de fuerza, constituido tanto por el flujo acústico circular como por los barridos corporales de las mudanzas, se pone en acción, la máquina sonora está dispuesta espacialmente y sólo entonces se ha vuelto apta al desplazamiento. Cuando la máquina sonora completa este proceso de adecuación y síntesis, que proyectando la tesis de Bergson podríamos llamar de sonido-movimiento ${ }^{8}$ (o sonoquinética), se da inicio al ciclo simbólico procesional. Diríamos que antes de su desplazamiento grupal, los chinos han hecho de su máquina sonora una cobertura como campo de fuerza vinculante, entre los integrantes del baile y entre estos y la potencia o entidad sagrada. Al iniciarse el movimiento procesional, en cambio, la máquina sonora adquiere una cobertura como ofensiva espacial o como campo de fuerza desvinculante del territorio de origen. En algunos casos, como por ejemplo en el baile de Loncura, las mudanzas buscan reproducir, en el momento de la detención, los gestos de desplazamiento procesional, de manera que la disposición de los ejecutantes, que en general suele mantenerse fija, se altera provisoriamente siguiendo un circuito de relevo que transforma el espacio interno del grupo en un corredor y le da movimiento en la inmovilidad. Cobertura como puro campo de fuerza o como ofensiva espacial, en ambos casos lo que se crea es un dispositivo de resistencia territorial ante las fuerzas del caos. Un dispositivo móvil, que crea un círculo de protección en un punto preciso de inflexión ritual desde el que puede desplazarse, hender el espacio profano, pero sin necesariamente salir del círculo creado, sino más bien moviéndose con él, dentro de él, como en una formación romana de ataque (formación de testudo o tortuga). Salvo que esta vez no hay un objetivo militar por neutralizar sino un espacio externo por mantener a raya en un trayecto que comienza y termina en el punto de partida, y que solo puede ser segmentado (nunca interrumpido), por las estaciones debidamente señaladas por un nuevo altar. La transición, de armado y desarmado de la máquina sonora, es asegurada por la intervención mediadora del alférez que, como veremos más

\footnotetext{
En la teología cristiana, la cruz es un máximo símbolo de compleción: «...podáis comprender, con todos los santos, cuál es la anchura y la longitud, la altura y la profundidad, y conocer el amor de Cristo que excede a todo conocimiento, para que os vayáis llenando hasta la total plenitud de Dios.» Pablo: Efesios, III, 18. Biblia de Jerusalén, 1976. En el fragmento titulado «Recuerdos de una hecceidad», Deleuze y Guattari, sostienen también que «un cuerpo no se define por la forma que lo determina, ni como una substancia o un sujeto determinado, ni por los órganos que posee o las funciones que ejerce. En el plano de consistencia, un cuerpo se define únicamente por una latitud y una longitud: vale decir el conjunto de los elementos materiales que le pertenecen bajo tales relaciones de movimiento y de reposo, de velocidad y de lentitud (longitud); el conjunto de los afectos intensivos del que es capaz, bajo tal poder o grado de potencia (latitud). Solo afectos y movimientos locales, velocidades diferenciales» (318).

8 Véase el primer capítulo de Matière et mémoire, relativo al problema de las imágenes-movimiento.
} 
abajo, se realiza desde una operación de devenir propiamente musical. Aunque se trata en apariencia de un canto sin ninguna relación formal con la máquina sonora, su fina trama de correspondencias no debe ser buscada en la emisión de la voz sino en la administración de velocidades e intensidades alternadas que ambos, canto y máquina sonora, comparten. El alférez es la auténtica figura sacerdotal del baile chino, ante la cual toda figura analogable sería redundante y antagónica. «El cura no sabe arar/tampoco enyugar un buey/ y él con su propia ley/cosecha sin sembrar»". Su intervención, fundamental, está restringida a los puntos de contacto con el culto general. El dominio del régimen de alternancias es el que permite evaluar las condiciones del espacio sagrado y las posibilidades de ingreso a él, desde un punto compartido por la comunidad parroquial al que, sin embargo, la institucionalidad oficial no tendría acceso ${ }^{10}$. El saludo y la despedida del ciclo procesional se realiza ante el altar principal, lugar de culto permanente que puede estar situado en la iglesia local, o en una gruta o un monumento religioso estable de la comunidad. Estos están secundados por las estaciones de la procesión, puntos de ingreso y salida intermedios, escalas del desplazamiento sagrado. El alférez interviene primero $a$ capela con un canto salmódico libre (ver Entonación 1 en Anexo), determinado solo por la métrica de los versos octosílabos que siguen el patrón popular del canto a lo divino, que debe ser acompasado con leves y continuos movimientos de inclinación, y de despliegue y repliegue de una bandera chilena. A veces el alférez canta décimas completas, algunas de las cuales incluyen versos recortados, en un registro regular de velocidad (ver Entonación 2 en Anexo). Al final de cada cuarteta salmódica, en cambio, el grupo de ejecutantes debe repetir los dos últimos versos y la melodía, pero más rápido y con tempo regular. Este es uno de los dos puntos de contacto expresivo, entre la actuación del alférez y la de los ejecutantes. El otro punto de contacto expresivo está dado por los cuidadosos movimientos de avance y retroceso que el grupo de chinos realiza siguiendo los movimientos del alférez, de cara siempre a la divinidad. En Caicai, por ejemplo, donde el altar está situado en el faldeo de una Colina, este movimiento será también un movimiento de ascenso y descenso. Solo cuando el alférez culmina su intervención, acto de consagración, la máquina sonora puede armarse e iniciar su desplazamiento que, hasta un nuevo alto, el alférez seguirá solo desde un punto de participación externo junto a la comunidad procesionante.

Recapitulando, en lo que se refiere al método, nuestra aproximación analítica se distancia tanto de la musicología, como etnomusicología y como musicología histórica, como de la etnografía y la antropología cultural. De la musicología, porque no describe un fenómeno propiamente musical, o representado como tal por los actuantes. De la etnografía o la antropología, porque no se está ante un sistema radical de alteridad cultural, y porque renunciamos, en consecuencia, a explicar el fenómeno ritual revelando su supuesta genealogía india o mestiza o prehispánica. La exigencia acrítica de traducir el fenómeno en una "posología» del mestizaje induce, creemos, erróneamente, a una hi-

Cuarteta cantada por el alférez oriundo de Maitencillo, Jaime Cisternas.

10 En Los Maquis se generó un conflicto cuando los encargados de la parroquia interrumpieron el saludo de los Chinos por la llegada del Obispo de Valparaíso. Más tarde el alférez Jaime Cisternas reacciona improvisando los versos siguientes: «Santísima cruz bendita/nunca se me va a olvidar/no me dejaron temprano/ de poderte saludar. No se vayan a enojar/por lo que voy a decirlyo soy un hombre de fely a la cruz vengo a cumplir. No me vayan a pedir/cantando no hay protesto/porque con la llega'el curalme sentí un poco molesto. Cantando soy muy abierto/santo madero sagrado/llegó ese personaje/mi baile me echaron pal lao". 
perconstrucción del objeto. Sin negar las ineluctables limitaciones del observador, hemos procurado insistir, en cambio, en un estudio centrado sobre el rito mismo, a la manera de una analítica existencial libre que procura comprender en las relaciones del cuerpo con el espacio y en las prolongaciones o proyecciones del cuerpo en el espacio, los valores y el sentido específicos del ritual, que busca, en un conjunto de gestos determinados por un régimen expresivo, una conexión con lo sagrado.

En lo que se refiere al objeto, comprendemos los bailes chinos como una operación expresiva no musical que, no obstante, se articula como triple potencia sonora de compleción espacial. El conjunto de gestos implicados en la ejecución de las flautas de chinos busca colmar el espacio posible: en la verticalidad del instante, como cluster de frecuencias continuo entre el ataque individual y el ataque grupal; en la horizontalidad de la secuencia temporal, como circularidad en la alternancia y encabalgamiento del ataque; en el sistema de barridos corporales de los ejecutantes que proyectan, en el movimiento y en el desplazamiento, la verticalidad y horizontalidad exigida en el plano sonoro, y del cual se vuelven una apoyatura o un «tallo» expresivo. Hemos articulado esta operación de triple compleción, desde la figura de una «máquina sonora» que cautela el desplazamiento del territorio ritual demarcado (acción nómade), sobre el territorio profano, y que proyecta el gesto sonoro en el gesto corporal. Por último el movimiento corporal, ritmado por un gesto de caída, es, simultáneamente la prolongación del gesto sonoro y su punto de partida.

\section{POTENCIAS SONORAS: EXPRESIÓN Y DEVENIR}

En su teoría del ritornelo, Gilles Deleuze situaba lo que podríamos llamar un régimen no musical del canto (que el autor hará extensivo a todo régimen preartístico de la expresión), en el ámbito de la espacialidad existencial. El ritornelo, literalmente asociado a las figuras premusicales y preautorales de la repetición en la música, como el «estribillo» o el tarareo, posee un sentido restringido cuando su disposición (agencement ${ }^{11}$ ) es sonora o está «dominada» por el sonido. ¿Cuándo y por qué tarareamos, cuándo decimos «tralalá»? Pero posee también un sentido general cuando designa por extensión a «todo conjunto de materias de expresión que traza un territorio y que se desarrolla en motivos territoriales, en paisajes territoriales (hay ritornelos motrices, gestuales, ópticos, etc.)» («De la ritournelle» en Mille Plateaux, 397). El ritornelo funda un territorio que no es el mundo, sino un mundo primario, allí donde solo primaban las fuerzas del caos (chaosmos). El ritornelo surge del hoyo negro, abre en el hoyo negro un territorio que es

11 Nos parece que la traducción generalizada al español del francés agencement, como agenciamiento, es errónea, en la medida en que para rendir el sentido de una palabra coloquial establece un neologismo complejo a partir del verbo "agenciar», que posee, en castellano, la significación restringida y diferente de «conseguir». Es por ello que traduciremos sistemáticamente agencement, simplemente como "disposición». "Según un primer eje, horizontal, una disposición comprende dos segmentos, uno de contenido, el otro de expresión -Deleuze rompe la distinción forma/contenido puesto que hay una forma del contenido y una forma de la expresión (NdT). Por una parte es disposición maquínica de cuerpo, de acciones y de pasiones, mezcla de cuerpos reaccionando unos sobre otros (herencia de Spinoza, NdT); por otra parte, disposición colectiva de enunciación, de actos y de enunciados, transformaciones incorporales que se atribuye a los cuerpos. Pero según un eje vertical orientado, la disposición tiene por una parte sus lados territoriales o reterritorializados, que la estabilizan, por otra puntas de desterritorialización que la llevan» (G. Deleuze y F. Guattari, Kafka - Pour une littérature mineure). 
también una cobertura contra las fuerzas externas. El ritornelo es un acto de territorialización que se realiza en dos fases: la del gesto expresivo como establecimiento de un punto de centro en el hoyo negro y la de su organización espacial. Aunque la teoría del ritornelo es transversal a la obra deleuziana y posee en su desarrollo algunas variantes, en su exposición central es presentada desde la figura de un niño que canturrea en la oscuridad para conjurar el miedo que lo invade, y cuya cancioncita esboza un «centro estable y calmo, en el seno del caos». Como el niño que salta en la cuna, mientras canta, dice Deleuze, la canción es ella misma un salto que «salta del caos a un comienzo de orden en el caos» (382). Ese comienzo traza en torno un círculo territorial e inaugura su propio proceso de organización espacial:

He ahí que las fuerzas del caos son mantenidas al exterior tanto como sea posible, y el espacio interior protege a las fuerzas germinativas de una tarea por cumplir, de una obra por realizar. Hay allí toda una actividad de selección, de eliminación, de extracción, para que las fuerzas íntimas terrestres, las fuerzas interiores de la tierra, no estén sumergidas, para que puedan resistir, o incluso puedan arrebatar algo al caos a través del filtro o el colador del espacio trazado. Por lo tanto, los componentes vocales, sonoros, son muy importantes: un muro de sonido, en todo caso un muro del que algunos ladrillos son sonoros. Un niño canturrea para recoger en sí las fuerzas del trabajo escolar que debe proveer. Una empleada canturrea, o pone la radio, al mismo tiempo que establece las fuerzas anti-caos de su obra. Los aparatos de radio o de TV son como un muro sonoro para cada hogar, y marcan territorios (el vecino reclama cuando está muy fuerte) («De la ritournelle» en Mille Plateaux, 382).

Pero es fundamental notar que si la cancioncita permite la traza del círculo territorial, su mantención depende del despliegue de un régimen de alternancia de intensidades y velocidades. Se trata aquí de una correspondencia directa con su propia exégesis de la obra de Nietzsche, cuyo "plan de consistencia», piensa Deleuze, no estaría constituido por formas en desarrollo (formas del mundo, formas de la filosofía), sino por velocidades y lentitudes entre partículas, por gestos de movimiento y gestos de reposo ${ }^{12}$. Nietzsche no conoce sino relaciones diferenciales de velocidad entre elementos, las mismas que Deleuze hace intervenir en la teoría del ritornelo, en su fase de territorialización:

Para obras sublimes como la fundación de una ciudad, o la fabricación de un Golem, se traza un círculo, pero sobre todo se marcha en torno al círculo como en una ronda infantil, y se combinan las consonantes y las vocales ritmadas que corresponden a las formas interiores de la creación como a las partes diferenciadas de un organismo. Un error de velocidad, de ritmo o de armonía sería catastrófico, puesto que destruiría al creador y a la creación trayendo de nuevo consigo las fuerzas del caos («De la ritournelle» en Mille Plateaux, 382).

Una vez constituido en sus dos fases, el territorio se revela finalmente como potencia triádica de territorialización, desterritorialización y reterritorialización. Puesto que se crea un territorio es posible concebir una salida fuera de sí, a un espacio nuevo, como prolongación o invaginación del espacio primario o bien como su abandono (desterritorialización). Por último, la cualidad de la salida determinará también la posibilidad del regreso y la modificación eventual del espacio de retorno (reterritorialización). «El gran

12 «Nietzsche no nos dice: sean rápidos —él mismo no era muy rápido—. Se puede ser rápido caminando muy lentamente. Otra vez es cuestión de relación diferencial entre velocidades y lentitudes. Se puede ser rápido sin moverse, se puede viajar en el lugar con una velocidad loca, se puede volver antes de haber partido" Gilles Deleuze, Curso de Vincennes del 8 de marzo de 1977. Transcripción realizada por Richard Pinhas. 
ritornelo se eleva a medida en que nos alejamos de la casa - dice Deleuze-, incluso cuando es para volver a ella, puesto que ya más nadie nos reconocerá cuando volvamos» (Qu'est-ce que la philosophie?, 181) ${ }^{13}$. "Ahora, al fin, se entreabre el círculo, se lo abre, se deja entrar a alguien, se llama a alguien, o bien uno mismo va afuera, uno se lanza. No se abre el círculo del lado en que se agolpan las antiguas fuerzas del caos, sino en otra región, creada por el círculo mismo. Como si el propio círculo tendiera a abrirse sobre un futuro, en función de las fuerzas en obra que abriga. Y esta vez, es para reunirse con las fuerzas del porvenir, fuerzas cósmicas» («De la ritournelle» en Mille Plateaux, 383).

Esta modalidades del ritornelo no son, según Deleuze, momentos sucesivos en una evolución, sino una misma cosa en un triple trayecto significante, en tres maneras de ser. El ritornelo posee los tres aspectos, los rinde simultáneamente, o los mezcla. «O bien el caos es un inmenso hoyo negro, y uno se esfuerza por fijar en él un punto frágil como centro. $\mathrm{O}$ bien se organiza en torno al punto una apariencia serena y estable: el hoyo negro se ha vuelto un estar en casa. O bien se injerta una escabullida sobre esta presencia, fuera del hoyo negro»» (Ibid., 382-383) ${ }^{14}$. Los tres aspectos del ritornelo poseen además en Deleuze una relación estrecha con su imagen del devenir como forma de repetición de la diferencia y también como flujo constructivo del deseo. Deseo no como investidura de objeto, sino como disposición, composición (agencement) de objetos, como invención de paisajes al interior del cual el deseo es pura modalidad de flujo. Modalidad de flujo que en Deleuze debe ser asimilada directamente a la noción de devenir. El contenido propio del deseo es, en Deleuze, el devenir ${ }^{15}$. Devenir que no es nunca imitar, o «transformarse en», o hacer «como

13 Esta sentencia, que puede parecer enigmática, debe contrastarse con su referencia permanente a la figura del «eterno retorno de lo mismo vuelto otro", que tiene una relación en Nietzsche con lo dionisíaco justamente como una forma no musical (o no apolínea) del sonido. Deleuze interpreta tal figura desde la óptica de un devenir que selecciona lo que vuelve, o lo que debe volver. Véase, del mismo autor, Différence et répétition, París, Epiméthée - P.U.F., 1968 y, también, Nietzsche et la philosophie, París, Bibliothèque de philosophie contemporaine - P.U.F., 1962.

14 En una entrevista grabada con Claire Parnet seis años después de la publicación de Mille Plateaux, Deleuze ofrece un ejemplo muy simple de su formulación inicial. «El ritornelo es un airecito: tralalá, lalá, lalá, tralalá. ¿Cuándo digo tralalá? [...] ¿Cuándo canturreo? En tres ocasiones: canturreo cuando recorro mi territorio, y sacudo el polvo de mis muebles - la radio suena al fondo-, vale decir cuando estoy en casa. Canturreo cuando no estoy en casa e intento volver a estar en casa. Cuando cae la noche - la hora de la angustia-, busco el buen camino y me infundo valor cantando tralalá. Voy hacia mi en casa (chez moi). Y además canturreo cuando digo: adiós, me voy, y en mi corazón llevaré (esto es la canción popular)... cuando salgo de mi en casa para ir a otra parte, pero ¿adónde? En otros términos, el ritornelo para mí está absolutamente ligado [...] a problemas de territorio y de salida o de entrada de territorio, es decir a problemas de desterritorialización" (l'Abécédaire).

15 De su exégesis de Nietzsche, Deleuze sustrae una representación del deseo particularmente inventiva. Si la voluntad de potencia significa querer la potencia, ella dependería de valores establecidos (honor, dinero, poder social) que determinan la atribución y la recognición de la potencia como objeto de deseo y voluntad. Pero quienes desean la potencia de esta manera son precisamente aquellos que Nietzsche llama los esclavos, los débiles. Querer la potencia es la imagen que los impotentes se hacen de la voluntad de potencia, o es la voluntad de potencia en su más bajo grado. En su más alto grado ella no consiste sino en dar y en crear. Su verdadero nombre, dice Zaratustra, es la virtud que da. La potencia no es lo que quiere la voluntad, interpreta Deleuze, sino lo que quiere en la voluntad. El psicoanálisis genera una imagen reductora del inconsciente en la medida en que ella va asociada a una concepción dislocada del deseo, sustentada en la primera representación de la voluntad de potencia. Pero en realidad no se desea a una persona, no se desea beber, no se desea un bonito traje. Mucho antes que eso se construye una disposición de objetos, un ordenamiento de cosas, espacios, imágenes, al interior del cual era posible querer a una persona, beber, tener un bonito traje (se desea, literalmente, en la voluntad). La disposición de elementos que permite el flujo de la investidura, su invención nunca idéntica, su creación, es verdaderamente el objeto del deseo. Asimismo, el inconsciente no es un teatro de marionetas que actúa siempre la misma obra - el Edipo, el complejo de castración-, y ante el cual toda distinción de representación, toda alteridad, debe 
si». No hay en el devenir un punto de partida y uno de llegada. El devenir es puro flujo-trayecto. Señalar qué o en qué devendría algo, carece de sentido, puesto que en la medida en que algo o alguien deviene, aquello en lo que deviene cambia tanto como sí mismo. Devenir,

no es imitar algo o alguien, no es identificarse con él. No es tampoco proporcionar vínculos formales. Ninguna de estas dos figuras de analogía conviene al devenir, ni la imitación de un sujeto ni la proporcionalidad de una forma. Devenir, es, a partir de las formas que se tienen, del sujeto que se es, de los órganos que se poseen o de las funciones que se cumplen, extraer partículas, entre las cuales se instauran relaciones de movimiento y de reposo, de velocidad y de lentitud, más próximas de lo que está deviniendo, y por las cuales se deviene. Es en este sentido que el devenir es el proceso del deseo («Devenir intense, devenir animal, devenir imperceptible» en Mille Plateaux, 334).

El devenir es también, por último, una antimemoria. La exigencia de un culto a la tradición, del reconocimiento de un origen o del conocimiento de una historia genealógica forman parte de las hiperconstrucciones que la antropología, los estudios folklóricos y en general, las ciencias sociales ilustradas han establecido a propósito de los bailes chinos. No hay recuerdo filogenético. Daniel Ponce sabe que aprendió el oficio constructor de su padre y que ha procurado transmitirlo a su hermano, pero ignora el origen del saber de su padre y la información, en sí, parece carecer de relevancia. No hay tampoco entre los chinos, sujeto folklórico, o sujeto popular, o ruralizado, o purificado, aislado en un campo o en una costa, en un área de preservación cultural. Más bien, puesto que son transversales a ella, es su propia integración a los circuitos de consumo generales y a la industria cultural, la que les permite devenir chinos en un punto de fuga o en un fuera de campo social. Obrero agrícola o portuario, técnico profesional, empleado bancario, profesor, estudiante universitario o investigador, no hay homogeneidad cultural ni socioeconómica entre los actuantes, y esa heterogeneidad es hoy su única y auténtica posibilidad. Se oye la radio, se ve la televisión, se tiene acceso a internet, se aprenden y cantan las canciones del circuito de reproducción mediático y discográfico. De veinte interpelados al azar, ocho tocan guitarra, uno de ellos piano y guitarra eléctrica, a dos de ellos les interesa la «música folklórica», a otros dos la «música selecta». Pero cada uno de ellos puede integrarse, los días de fiesta, a la fuerza sin memoria y sin música, de su baile chino. Hay en juego, no obstante, una forma de memoria o de memorias, pero ninguna de ellas tiene que ver, en lo esencial, con los circuitos de emergencia o de evanescencia de lo moderno o lo occidental como patrones de mayoría:

Hay sin duda una memoria molecular, pero como sistema de integración a un sistema molar o mayoritario. El recuerdo tiene siempre una función de reterritorialización. Por el contrario, un vector de desterritorialización no está de ninguna manera indeterminado, sino en compromiso directo sobre los niveles moleculares, y tanto más cuanto más está desterritorializado: es la desterritorialización la que hace sostenerse al conjunto de los componentes moleculares. Se opone desde este punto de vista un bloc de infancia, o un devenirniño, al recuerdo de infancia: 〈un〉 niño molecular es producido [...] 〈un〉 niño coexiste con nosotros, en una zona de vecindad o en un bloc de devenir, sobre una línea de desterritorialización que nos lleva a ambos - contrariamente al niño que hemos sido, del que nos acordamos o con el que fantaseamos, el niño molar del que el adulto es el porvenir (Ibid., 360).

ser suprimida y supeditada a una matriz sintética. El inconsciente es el sustrato de máquinas deseantes que no invisten el mundo de sus afectos, sino que devienen permanentemente con el mundo y en el mundo. Puro devenir creativo que delira la tribu, el cosmos, los continentes. He ahí el sustrato de una filosofía que opera estéticamente y que inventa, como la obra de arte, sin por ello dejar de ser filosofía. 
Por exhaustividad, en el plan de redacción de Mille Plateaux las nociones de devenir y ritornelo son abordadas en capítulos separados aun cuando, como insiste Deleuze en sus trabajos preparatorios, y particularmente en sus cursos de Vincennes, ambas están determinadas en una relación de reciprocidad. La tesis vinculante es la siguiente: si la identidad del ritornelo está determinada por la territorialización de la voz, el devenir musical del sonido depende de un proceso de desterritorialización de la voz. «Si el ritornelo es la voz que canta ya, la voz territorializada, aunque sea en un hoyo negro, la música, ella, comienza con la desterritorialización de la voz» (Curso de Vincennes). Deleuze representa ese proceso como una maquinación de la voz fuera de sí y, por lo tanto, como una disposición propiamente musical de la voz, mientras que en el ritornelo la voz posee una disposición que involucra elementos no musicales. "Cuando la voz al estado puro es extraída y produce una disposición propiamente vocal, ella surge como voz sonora desterritorializada» (Curso de Vincennes). ¿Pero qué debemos entender por voz? ¿Qué querría decir que la voz se desterritorializa? La voz no es necesariamente la voz humana, sino toda forma primaria de expresión sonora. Y cuando Deleuze toma el ejemplo del canturreo del niño en la oscuridad, para remitirnos al ritornelo, no es para instituir la supremacía del canto sobre otras formas de emisión sonora, sino por el contrario, para exponer una forma expresiva que, siendo humana, es anterior en su identidad al canto, como expresión musical. «Hay cosas que aún no son música y que, no obstante, son muy próximas a la música. Hay tipos de canto que aún no son música» (Curso de Vincennes). De hecho, el canto musical, y la obra de arte, encarnan, como bloc de afección y de sensación, un devenir no humano del hombre ${ }^{16}$. El primer canto, antes del canto, es el canto de un niño que canta con la voz del niño, o el canto del hombre que canta con la voz del hombre, o el canto de la mujer que canta con la voz de la mujer. Aquí el niño, el hombre o la mujer, están territorializados como niño, como hombre o como mujer. Su identidad está alineada con su determinación natural o «mayoritaria» ${ }^{17}$. Pero hay un momento en la expresión sonora en Occidente moderno, por ejemplo en los albores de la ópera, en que César, Alejandro o Aquiles son vocalmente encarnados por un castrati, o en donde las voces soprano no pueden ser cantadas por mujeres sino solo por niños, o por contratenores. Este ejemplo, extremo y literal, revela una condición de toda disposición propiamente musical. Desde el punto de vista de la expresión, devenir musical implica una desterritorialización de la voz y — para este caso puntual- desde el punto de vista del contenido, la superación de los sexos. Deleuze piensa que la primera gran desterritorialización de la voz en Occidente, habiendo encontrado una disposición específica, dispuesta sobre sí misma, maquinada sobre sí misma, va a ser el devenir musicalmente niño. Es revelador en ese sentido que tanto en la tradición italohispánica como en la inglesa, las voces determinantes de la música vocal hayan sido la soprano, la contralto y la contratenor, todas voces de niño, o hechas para un niño:

No se trata de cantar o de hacer la voz como canta un niño; si se quiere el niño está completamente artificializado. Habría que distinguir al niño molar que canta, no musicalmente, el niño del pequeño ritornelo, y el niño molecular, dispuesto por la música. Incluso cuando es

16 «Los afectos son precisamente estos devenires no humanos del hombre, como los perceptos (incluyendo a la ciudad) son los paisajes no humanos de la naturaleza. [...] Todo es visión, devenir. Se deviene universo. Devenir animal, vegetal, molecular, devenir cero» (Qu'est-ce que la philosophie?, 160).

17 Ello caracteriza en Deleuze su función «molar» por oposición a su función «molecular», desterritorializada y minoritaria. 
un niño el que canta [...], se requiere una operación de artificio musical mediante la cual el niño molar deja de serlo para devenir molecular [...] El niño tiene por lo tanto un devenir musicalmente niño. Lo que significa que el niño que la música deviene, o que la música hace devenir, es él mismo un niño desterritorializado como contenido, del mismo modo que la voz como expresión es una voz desterritorializada. No se trata de imitar al niño que canta, se trata de producir un niño sonoro, es decir, desterritorializar al niño al mismo tiempo que se desterritorializa la voz (Curso de Vincennes).

No basta ser un niño para devenir niño. El niño mismo debe pasar por una operación de devenir niño, abierta al hombre, a la mujer. Por ejemplo, para devenir niño habrá que pasar por la operación italiana del castrati, disposición maquínica a la que nada falta (el castrati está en un devenir mujer que ninguna mujer tiene, está en un devenir niño que ningún niño tiene). Pero toda forma de desterritorialización contiene en potencia un movimiento de reterritorialización. La música sinfónica del siglo XIX abre en apariencia un proceso de reterritorialización de la voz. En Wagner o en Verdi, el cantante será hombre que responde con voz de hombre a la voz de mujer. Es lo que Deleuze llama un retorno a la «máquina binaria». Pero ello no implica una pérdida de su devenir musical. Cuando, en la música instrumental, el instrumento deviene primero en relación a la voz, la voz deviene a su vez un factor de reterritorialización. La atención debe ser puesta en el hecho de que la voz deviene instrumento no vocal, por asimilación a la organización instrumental. Si simplemente se considera a las voces como voces,

ellas vuelven a caer en la determinación natural o territorial hombre-mujer, pero al mismo tiempo ellas son musicales desde otro punto de vista: en su relación con el instrumento del que son el símil, en el conjunto de la maquinación donde, por último, no habrá ya ninguna diferencia de naturaleza entre el sonido de la flauta y el timbre de la voz. Se habrá pasado a un nuevo tipo de disposición [...] La forma de expresión musical ha cambiado: en lugar de maquinación de la voz hay maquinación sinfónica, maquinación instrumental de la que la voz no es sino un elemento igual a los otros. Pero de pronto la forma del contenido cambia también, y habrá un cambio en los devenires. La forma del contenido sigue siendo el devenir, pero verán como una imposibilidad de volver a alcanzar al estado puro lo que hacía lo esencial de la música vocal, vale decir el devenir mujer y el devenir niño. Verán una apertura sobre otros devenires (Curso de Vincennes).

Deleuze sostiene que, en su estadio precedente, los devenires de la música, devenires mujer, devenires niño, alcanzaban una frontera, una forma límite, que anticipaba simultáneamente la reterritorialización del canto y su disposición sinfónica. Dicha frontera era el devenir animal, y sobre todo, el devenir pájaro. El tema del devenir es así asociado radicalmente a la producción musical de un pájaro desterritorializado. Una vez más, la música no reproduce el canto del pájaro, ella produce un canto de pájaro desterritorializado. El carácter fronterizo, liminar, de tal operación, reside en su capacidad de liberar las fuerzas que se abren sobre un devenir elemental. La nueva música instrumental o sinfónica ya no tiene el control de los devenires niño y de los devenires mujer, pero abre y se abre a otros devenires, como «liberación de los devenires animales propiamente sonoros, propiamente musicales. Devenires potencias elementales, devenires elementales» (Curso de Vincennes).

Es común leer, entre los antiguos estudiosos de la cultura tradicional, descripciones que asocian el sonido de las flautas de chinos con el ruido de un animal, aunque, a decir verdad, en todas ellas la comparación es solo aproximativa, como si el graznido o el grito de un pájaro, o una bestia, fueran la reminiscencia inexacta de un sonido anterior que 
permanecería esquivo a toda identificación. Lo que prima, en todo caso, es la extrañeza, la escasa o relativa familiaridad con que se presentan al registro las fuerzas audibles $\mathrm{y}$, por sobre todo, el efecto siniestro de esa ambigüedad que Freud abordará desde la perspectiva de lo que denomina Das Unheimlich, lo extraño-familiar. Uribe describe el sonido de las flautas en 1958 como «extrañísimo y angustioso, salvaje, como de pájaros marinos angustiados» (Uribe Echevarría, Contrapunto de alféreces, 16) y luego, en 1974, como «sonidos animales que han sido comparados con el rebuzno de un burro, el graznido del ganso y también con chillidos de gaviotas asustadas» (Uribe Echevarría, La Virgen de Andacollo). Latcham se refiere a él como sordo y monotónico, semejante al graznido de un ganso o un cisne, para agregar contradictoriamente que «como no hay dos que tengan el mismo tono, el ruido producido cuando están sonando 400 o 500 de estos instrumentos es desesperante» (cit. en Contrapunto de alféreces, 29). O bien, como señalan Pumarino y Sangüeza, «se asemeja al graznido de una inmensa bandada de gansos [...] ensordecedora y a la vez cautivante» (Pumarino y Sangüeza, Bailes chinos). En el caso de las referencias de Uribe y Latcham, la angustia, el miedo o la desesperación, parecieran no ser solo un efecto de la audición de las flautas, sino un atributo del ente emisor que redoblaría así su distancia de lo humano, de lo propio y de lo familiar. Algo distinto ocurre cuando son los mismos ejecutantes de los bailes los que caracterizan su patrón sonoro, el modo adecuado de la emisión, desde la figura del «ganseo». Lo adecuado es designado aquí solo instrumentalmente por su asociación zoomórfica, para señalar justamente que el sonido por alcanzar está aún más lejos de lo animal, en las fuerzas puras de la naturaleza, en un punto en el que ellas mismas se confunden con las fuerzas del caos. Solo que esta vez se está dentro de ellas. La ejecución de las flautas las ha invocado como fuerzas de proximidad, las ha situado en el espacio propio como si, paradójicamente, la máquina sonora se asimilara con la absoluta exterioridad del hombre, como si ella misma absorbiera primero las fuerzas del caos, las volviera su medio familiar, para resistirlas luego verdaderamente en un punto absoluto de desplazamiento existencial, que la pondría de lleno en presencia de lo sagrado. La compleción y circularidad del movimiento y del sonido, son la expresión única y directa de las fuerzas que la abarcan y la despliegan como hierofanía. El devenir no musical de los chinos, de su máquina sonora, reside en una operación de desterritorialización de lo sagrado que se reterritorializa en la voz. La intercesión del alférez, acto de armado y desarmado, de entrada y salida de la máquina sonora, es la operación musical que se completa en los actuantes como movimiento y sonido de un devenir no musical. Pero como el alférez, caminando durante la procesión por un espacio externo a la máquina sonora, a la espera del momento en que tendrá que revertir su movimiento de arranque, así también la fuerza del devenir no musical determina en última instancia a la disposición musical que la espera como en un fuera de campo de las potencias sonoras. Y a la inversa, la representación de lo musical no aparece alcanzable sino revelando, o procurando revelar los hilos o el andamiaje del trayecto que la sostienen desde lo no musical al que ella no deja de regresar o, como diría Deleuze ${ }^{18}$, de las fuerzas no audibles que, por un momento, ella pudiera hacer oír.

18 Así la música no expresa lo audible, ella «hace audible algo que no lo es, hace audible la música de la tierra -o inventa, exactamente, casi como el filósofo, hace pensables fuerzas que no son pensables, que son más bien de una naturaleza bruta, de una naturaleza brutal. [...] (La música es) esa comunión de los pequeños ritornelos con el gran ritornelo [...] y su potencia de llevar a un nivel verdaderamente cósmico, como si las estrellas se pusieran a cantar un airecito de cencerros de vaca, una airecito de pastor, o más bien al revés: los cencerros de vaca se ven elevados de repente al estado de ruido celeste, o de ruido infernal...» (Gilles Deleuze, "O, como ópera», en l'Abécédaire de Gilles Deleuze). 
ANEXO

\section{RECUADRO 1}

\section{ACÚSTICA DE LA COMPLECIÓN ESPECTRAL}

Los instrumentos musicales operan en su gran mayoría gracias a la interacción entre un estímulo o excitación y un cuerpo resonante o resonador. La geometría y propiedades físicas del resonador determinan sus posibles modos de vibración, los que al ser acoplados a moléculas de aire, irradian sonido. El resonador es por lo tanto quien define los modos de vibración posibles y es la excitación la responsable de inyectar la energía necesaria para que los modos disponibles produzcan sonido.

En el caso de instrumentos de viento la «disposición» del resonador a ser excitado se cuantifica a través de la admitancia de entrada, medida que relaciona la velocidad de las partículas con su presión acústica. En la mayoría de las flautas el resonador es cilíndrico y abierto en los dos extremos, por lo que muestra una buena disposición a ser excitado por vibraciones cuyas frecuencias ocurren en múltiplos enteros de una frecuencia fundamental (fo), creando una serie de armónicos ubicados en 2, 3, 4, etc., veces la frecuencia de la nota fundamental.
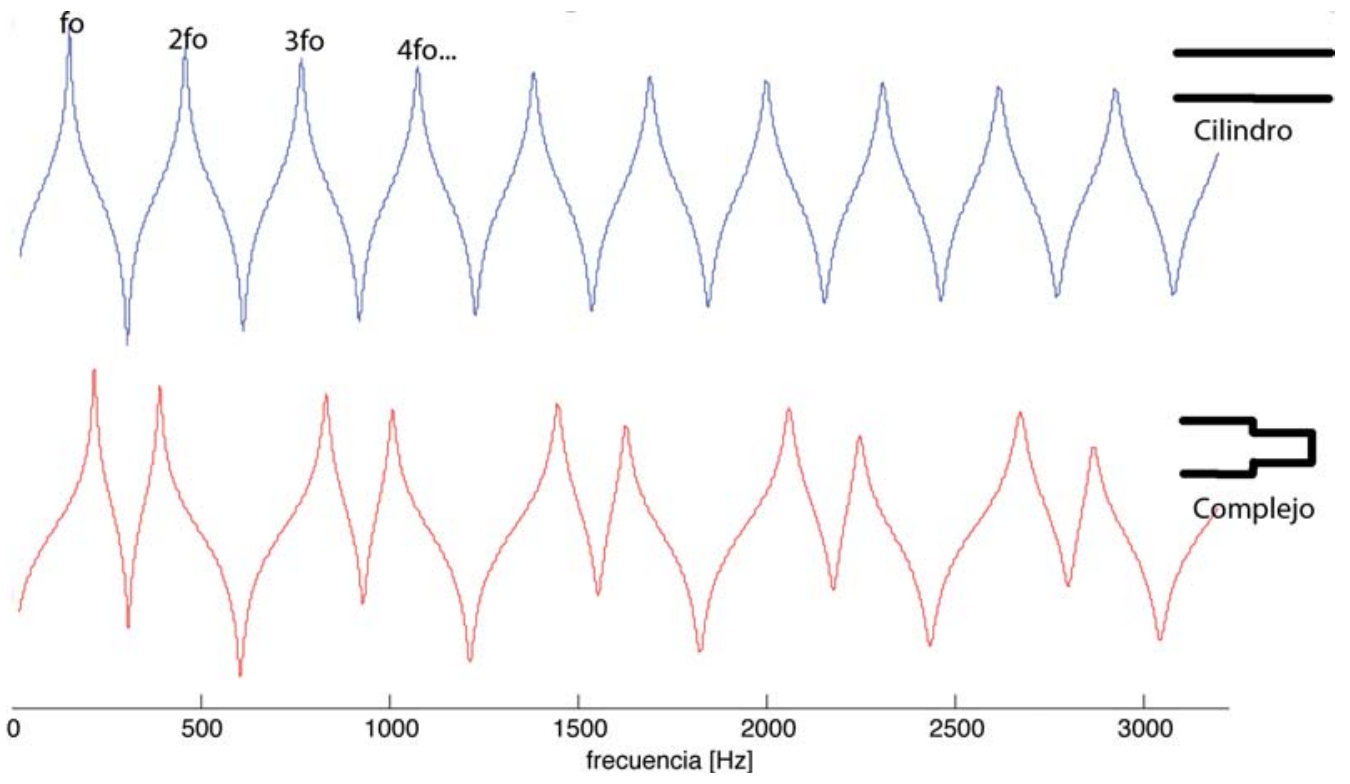

Figura 1: Comparación entre los modelos de admitancia de entrada de un resonador cilíndrico (arriba) y la de un resonador complejo (abajo) de similar largo total. En el primer caso las crestas de la función de admitancia se ubican en múltiplos enteros de la frecuencia fundamental, en cambio el segundo muestra una estructura de crestas menos regular. 
En el caso de las flautas de chinos el resonador es un tubo complejo (Pérez de Arce), que está formado por dos cilindros de distinto diámetro, conectados a través de una transición abrupta y con un extremo sellado. El ajuste adecuado entre el largo de los cilindros produce una admitancia con crestas espaciadas irregularmente, formando una estructura de doble periodicidad, coherente con la duplicidad de los tubos que la forman.

Al ser ejecutadas, las flautas irradian sonidos cuya energía se concentra en regiones cercanas a las crestas de la función de admitancia como muestra la siguiente figura:

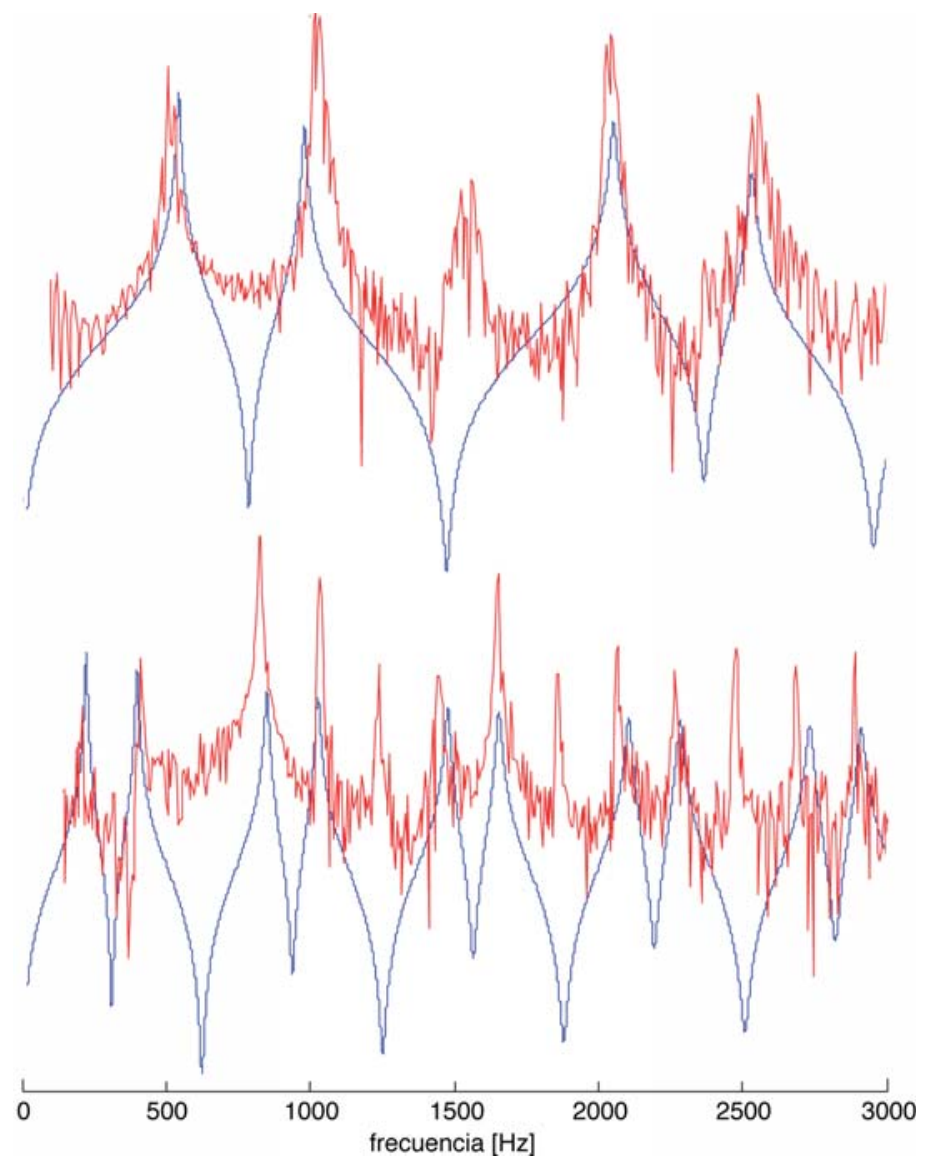

Figura 2: Comparación entre el modelo de admitancia de entrada desarrollado para un tubo complejo (azul) y espectro de frecuencia del sonido irradiado (rojo) obtenido a partir de grabaciones en terreno de dos flautas de chinos de distinto largo: una catarra (arriba) y una puntera (abajo). En ella se observa la concordancia en la posición de las crestas entre admitancia y espectro.

La amplitud de las crestas de la función de admitancia se ve afectada por la porosidad de la pared interna del instrumento, debido al aumento de las pérdidas visco-térmicas que experimentan las ondas acústicas al propagarse al interior del resonador. Es por esto que las flautas son humedecidas interiormente antes de ser tocadas, incrementando así las crestas de la función de admitancia y facilitando la producción sonora del instrumento. 


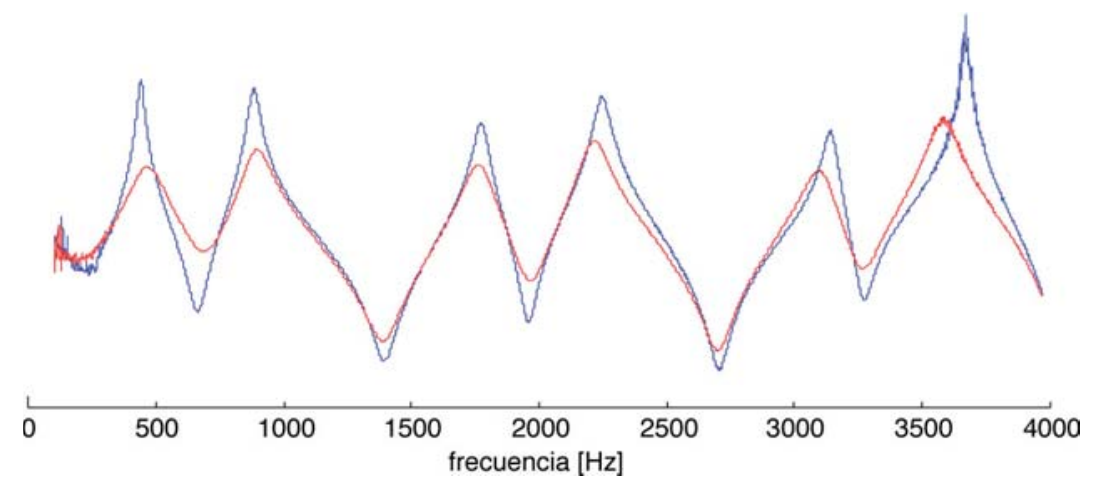

Figura 3: Comparación entre la admitancia de entrada de una flauta seca (roja) y una humedecida interiormente (azul). La mayor amplitud observada en la flauta humedecida, que se explica por la porosidad de las paredes interiores, permite mayor facilidad en la producción de sonido.

La excitación en las flautas de chinos es producida por un chorro de aire con características poco usuales entre las flautas: tiene una constitución turbulenta que alcanza velocidades de hasta aproximadamente $75 \mathrm{~m} / \mathrm{s}$. Para lograr estas velocidades los ejecutantes deben generar en sus pulmones una presión del orden de 3500 pascales, vale decir, cuatro veces mayor que la observada en el registro medio de flautas traversas. El conducto de salida entre los labios tiene una apertura típica de $0.8 \mathrm{~cm}^{2}$ de superficie, por lo que el flujo de aire expelido rodea los 6 lts/seg. Considerando que la capacidad pulmonar máxima del ser humano es en promedio de 4 lts. de aire, la duración de cada sonido no puede ser mayor que 0.7 segundos, lo que sin duda, condiciona el pulso de la marcha.

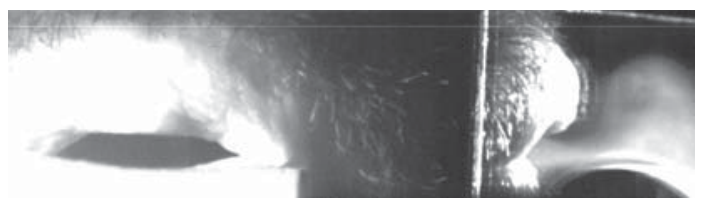

Figura 4: Vista frontal (izquierda) y lateral (derecha) de los labios de un flautista ejecutando una flauta de chino. En ella se observa la apertura típica de los labios así como la estructura turbulenta del chorro de aire, que ha sido teñido con humo para su visualización.

Una excitación de esa envergadura, que los ejecutantes logran en parte gracias a saltos y flexiones balanceando la hiperventilación con el gasto muscular, utilizada eficazmente es capaz de inyectar energía en casi todos los modos disponibles, e incluso, debido al comportamiento no lineal del chorro de aire, en zonas del espectro donde el resonador opone resistencia a la vibración, como muestra la Figura 2. La producción de tal sonido exige maestría en el control de la presión de aire, acuciosidad en el direccionamiento del chorro de aire y un instrumento adecuado.

La acción combinada del resonador complejo y la excitación turbulenta hace que el sonido producido por las flautas de chinos llene de energía de manera muy excepcional el espectro de frecuencias, generando el característico sonido rajado (Pérez de Arce: 1993). 

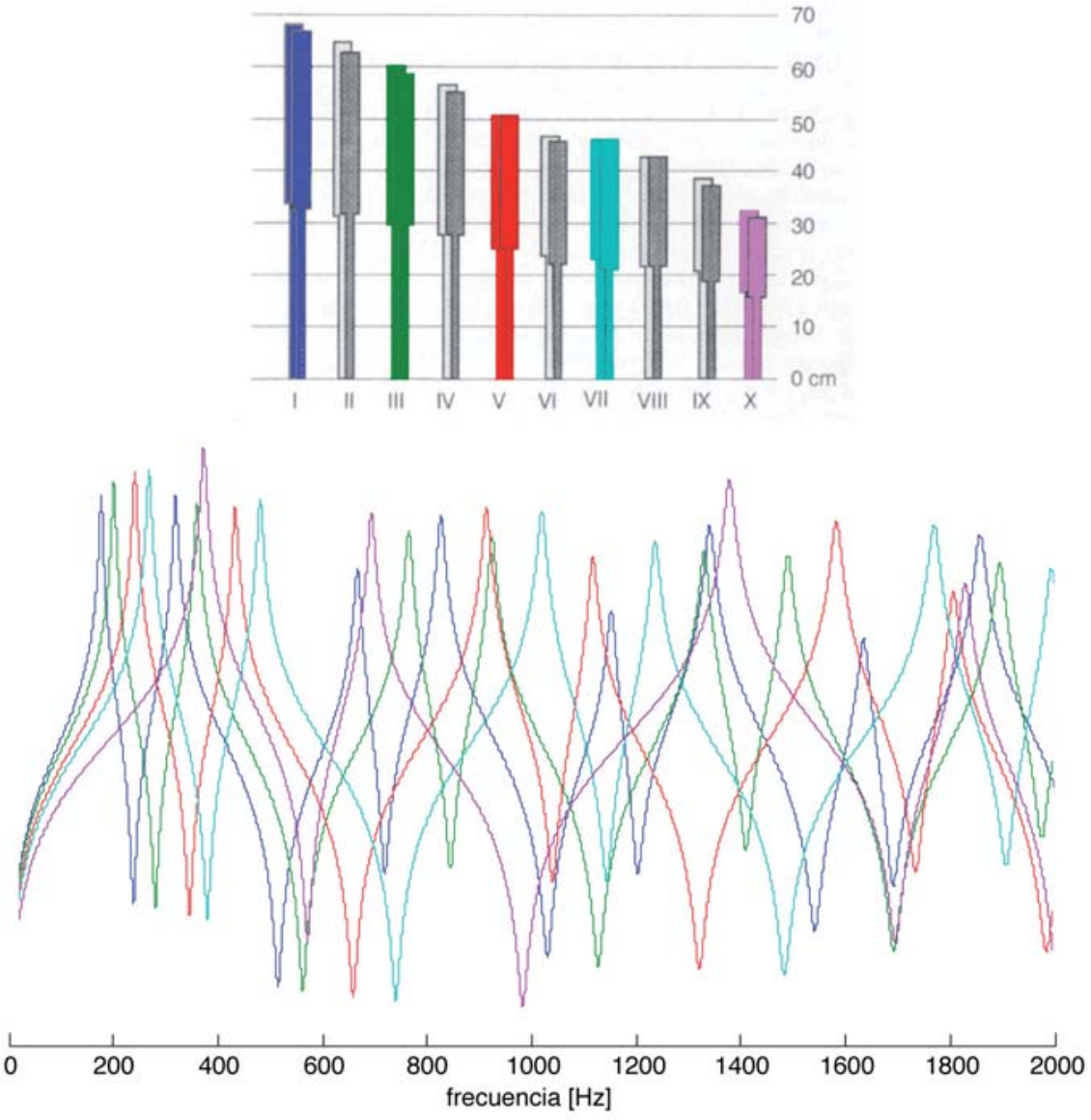

Figura 5: Ensamble de flautas con detalle de la geometría del tubo complejo (arriba, tomado de Pérez de Arce:

1998) y la admitancia de entrada (abajo). Para claridad de la representación se incluye la admitancia de un subconjunto de las flautas, las que son individualizadas utilizando un color similar en ambos gráficos. Se observa cómo el sonido del ensamble llena gran parte del espectro audible.

Aunque un ensamble de flautas o baile chino está conformado por entre 5 y 12 pares de flautas de distintos largos, para describir el efecto de cluster del sonido del ensamble se ha considerado un baile de 10 pares, cuyos largos varían entre 30 y $70 \mathrm{~cm}$, como se observa en la Figura 5. En él cada pareja de flautas de igual tamaño es representada por un color ${ }^{1}$. Al generar sonido, cada pareja de flautas aporta energía en las zonas del espectro que coinciden con las crestas de su función de admitancia, y al estar estas desfasadas entre ellas, llenan de energía gran parte del espectro audible.

1 Para dar mayor claridad a la figura se han modelado y graficado solamente las curvas de admitancia de un subconjunto del baile. Las curvas de admitancia de aquellas flautas que no están coloreadas pueden ser fácilmente bosquejadas interpolando las curvas de sus vecinas. 


\section{RECUADRO 2}

\section{ALTURA PERCEPTUAL}

Un sonido armónico es aquel que está compuesto por una serie de componentes sinusoidales cuyas frecuencias se ubican en, o muy cerca de, múltiplos de la componente más grave o frecuencia fundamental, como es el caso de instrumentos de resonador cilíndrico. Al crearse un sonido con energía dispuesta de esta manera, el oído percibe e integra esta serie de vibraciones superpuestas como un solo sonido con una altura determinada correspondiente a la frecuencia fundamental, y un timbre específico. Aun más, el oído es capaz de inferir la altura de un sonido armónico aun cuando no estén presentes las componentes sinusoidales más graves. Esta deducción se logra gracias a la relación entre las frecuencias de los armónicos superiores.

En el caso de las flautas de chinos, los armónicos no se encuentran regularmente espaciados, lo que dificulta la percepción de una altura determinada, generando una primera sensación de sonido «sin altura». Sin embargo, contar con una estructura armónica clara que, pese a no ser regular tampoco es caótica, sino doblemente periódica, logra sugerir en el auditor atento una altura determinada a partir de la relación entre sus armónicos, lo que hace posible la comparación entre dos notas diferentes.

\section{ENTONACIÓN 1}
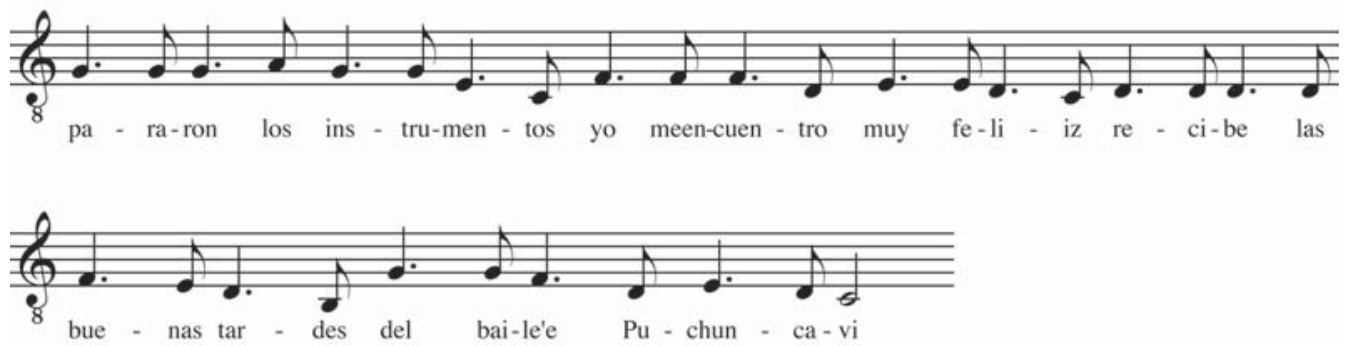


\section{ENTONACIÓN 2}
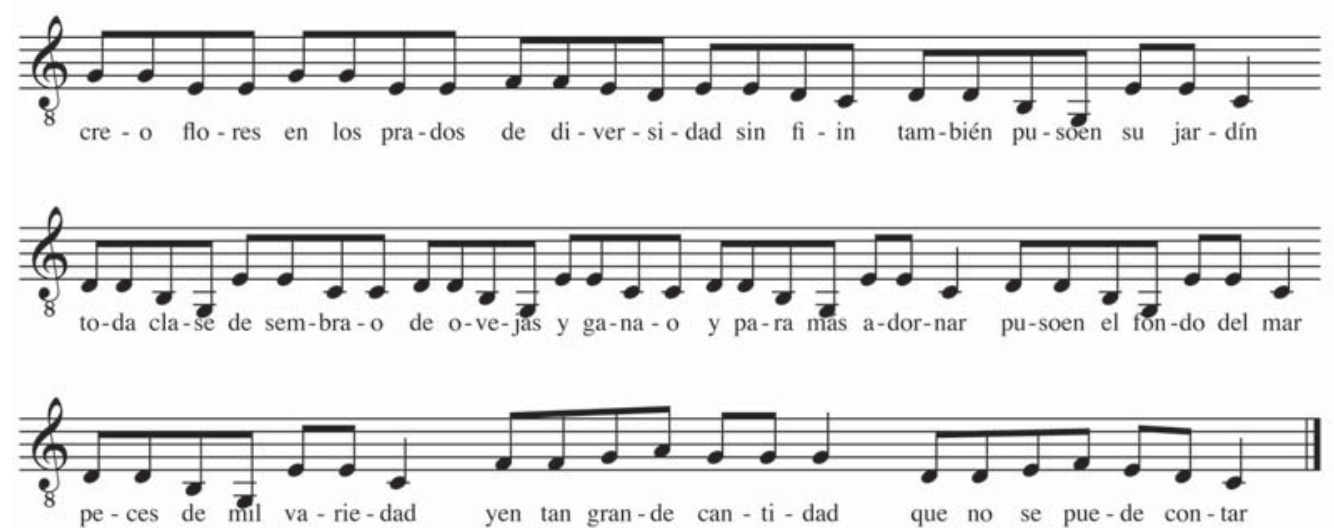

\section{REFERENCIAS}

Bartók, Béla. Escritos sobre música popular. México: Siglo XXI, 1987. Medio impreso. Bergson, Henri. Matière et mémoire: essai sur la relation du corps à l'esprit. París: P.U.F., 1959. Medio impreso.

Biblia de Jerusalén. 1976. Medio impreso.

Chaigne, Antoine y Jean Kergomard. Acoustique des instruments de musique. París: Belin, 2008. Medio impreso.

Deleuze, Gilles. Curso de Vincennes del 8 de marzo de 1977 (transcripción de Richard Pinhas). Medio impreso.

—. Différence et répétion. París: Epiméthée - P.U.F., 1962. Medio impreso.

- Nietzsche et la philosophie. París: P.U.F., 1962. Medio impreso.

—. L’Abécédaire de Gilles Deleuze. Montparnasse: Arte Vidéo, 1997. Medio impreso.

Deleuze, Gilles y Félix Guattari. Kafka - Pour une littérature mineure. París: Les éditions de Minuit, 1975. Medio impreso.

—. Mille Plateaux. París: Les éditions de Minuit, 1980. Medio impreso.

—. Qu'est-ce que la philosophie? París: Les éditions de Minuit, 1991. Medio impreso.

Fletcher, Neville H. y Thomas D. Rossing. The Physics of Musical Instruments. USA: Springer, 1999. Medio impreso.

Henríquez, Alejandro. Organología del folklore chileno. Valparaíso: Ed. Universitaria, 1973. Medio impreso.

Kinsler, Lawrence E.; Frey, Austin R.; Coopens, Alan B. y James V. Sanders. Fundamentals of Acoustics. U.S.A.: John Wiley \& Sons, Inc., 2000. Medio impreso.

Latcham, Ricardo. «La Virgen de Andacollo y sus danzas». Anales de la Universidad de Chile 126 (1910, enero-junio). Medio impreso. 
Mercado, Claudio. «Música y estados de conciencia en fiestas rituales de Chile central. Inmenso puente al universo». Revista Chilena de Antropología 13 (1995). Medio impreso.

— «Ritualidades en conflicto: los bailes chinos y la Iglesia Católica en Chile Central». Revista Musical Chilena 56/197 (2002). Santiago, Universidad de Chile. Medio impreso.

Mercado, Claudio y Galdames, Luis. De todo el universo entero. Fondo Matta - Museo Chileno de Arte Precolombino, 1997. Medio impreso.

Mercado, Claudio y Rondón, Víctor. Con mi humilde devoción. Ed. Carlos Aldunate del Solar. Santiago: Morgan, 2003. Medio impreso.

Pérez de Arce, José. «Sonido Rajado: The Sacred Sound of Chilean Pifilca Flutes». The Galpin Society Journal 51 (1998, julio). Medio impreso.

— «olifonía en fiestas rituales de Chile Central». Revista Musical Chilena 185 (1996). Santiago, Facultad de Artes, Universidad de Chile. Medio impreso.

— «iku». Revista Andina 2 (1993). Cuzco. Medio impreso.

— «Música prehispánica y sus ecos en el Chile actual». Música en la Piedra. Santiago: Museo Chileno de Arte Precolombino, 1995. Medio impreso.

— «Armonía Andina». Actas Colombinas $2 / 6$ (1992). La Serena: Universidad de La Serena. Medio impreso.

— «Cronología de los instrumentos sonoros del Área Extremo Sur Andina». Revista Musical Chilena, 166 (1986, julio-diciembre). Santiago, Universidad de Chile. Medio impreso.

— «Flautas arqueológicas del extremo sur andino». Boletín del Museo Chileno de Arte Precolombino 2 (1987). Santiago. Medio impreso.

Pumarino, Ramón y Sangüeza, Arturo. Bailes chinos en Aconcagua y Valparaíso. Santiago: Ed. de la Consejería Nacional de Promoción Popular, 1968. Medio impreso.

Ruiz, Agustín. «Hegemonía y marginalidad en la religiosidad popular chilena: los bailes ceremoniales de la Región de Valparaíso y su relación con la Iglesia Católica». Revista Musical Chilena, 49/184 (1995, julio-diciembre). Medio impreso.

Uribe Echevarría, Juan. «Contrapunto de alféreces en la provincia de Valparaíso». Ediciones de los Anales de la Universidad de Chile 1 (1958, serie celeste). Santiago. Medio impreso.

Uribe Echevarría, Juan. «La Virgen de Andacollo y el Niño Dios de Sotaquí». Valparaíso: Ediciones Universitarias de Valparaíso, 1974. Medio impreso.

Wolfe J., et al. «Acoustic impedance spectra of classical and modern Flute». Journal of Sound and Vibration 243 (2001). 127-144. Medio impreso.

Wright, H. A. K. y Campbell, D. M. «Analysis of the Sound of Chilean Pifilca Flutes». The Galpin Society Journal 51 (1998, julio). Medio impreso.

Recepción: 21 de marzo de 2010 Aceptación: 13 de mayo de 2010 